\title{
Bone mineral density in apparently healthy young men aged 18-30 years
}

\author{
L. K. Forsythe, J. M. W. Wallace, S. M. P. Kerr and M. B. E. Livingstone \\ Northern Ireland Centre for Food and Health, University of Ulster, Coleraine BT52 1SA, UK
}

Osteoporosis, a disease characterised by low bone mineral density (BMD), is estimated to cost the NHS £2.3 billion per year ${ }^{(1)}$. BMD is attained throughout childhood and adolescence, with peak bone mass reached by early adulthood ${ }^{(2)}$. Studies till date have mainly focused on assessing the BMD of groups at increased risk of fractures, namely postmenopausal women and elderly populations, however, low BMD is also evident in younger adults ${ }^{(3)}$. Therefore, the aim of the current study was to investigate BMD in apparently healthy young men aged 18-30 years living in Northern Ireland.

Height and weight were measured and BMI calculated among consenting volunteers ( $n$ 98). Fat mass (FM, kg) and fat-free mass (FFM, kg) were measured by air-displacement plethysmography (BodPod ${ }^{\circledR}$; Life Measurement Inc, USA), and BMD $\left(\mathrm{g} / \mathrm{m}^{2}\right)$ at the lumbar spine, left femur and total body were measured using Dual-energy X-ray Absorptiometry (DXA) scans (Lunar Prodigy, GE Healthcare, UK). Leisure-time physical activity (LPA; MET h/week) levels were assessed using a self-reported questionnaire.

For the group, mean and SD of age, weight, BMI, FM, FFM, lumbar spine BMD, left femur BMD, total body BMD and LPA were 23.28 and 3.3 years, 78.31 and $14.0 \mathrm{~kg}, 24.91$ and $4.1 \mathrm{~kg} / \mathrm{m}^{2}, 14.10$ and $9.3 \mathrm{~kg}, 64.47$ and $7.5 \mathrm{~kg}, 1.25$ and $0.2 \mathrm{~g} / \mathrm{m}^{2}, 1.18 \mathrm{and} 0.2 \mathrm{~g} / \mathrm{m}^{2}, 1.27 \mathrm{and}$ $0.1 \mathrm{~g} / \mathrm{m}^{2}$ and 63.21 and $45.4 \mathrm{METh} /$ week, respectively.

\begin{tabular}{|c|c|c|c|c|c|c|}
\hline & $\begin{array}{l}\text { Weight } \\
(\mathrm{kg})\end{array}$ & $\begin{array}{l}\mathrm{FM} \\
(\mathrm{kg})\end{array}$ & $\begin{array}{l}\text { FFM } \\
(\mathrm{kg})\end{array}$ & $\begin{array}{l}\text { BMD spine } \\
\left(\mathrm{g} / \mathrm{m}^{2}\right)\end{array}$ & $\begin{array}{l}\text { BMD femur } \\
\left(\mathrm{g} / \mathrm{m}^{2}\right)\end{array}$ & $\begin{array}{l}\text { BMD total body } \\
\left(\mathrm{g} / \mathrm{m}^{2}\right)\end{array}$ \\
\hline FM (kg) & $0.75^{* *}$ & & & & & \\
\hline FFM $(\mathrm{kg})$ & $0.77 * *$ & $0.23 *$ & & & & \\
\hline Spine BMD $\left(\mathrm{g} / \mathrm{m}^{2}\right)$ & $0.30 * *$ & 0.03 & $0.52 * *$ & & & \\
\hline Femur BMD $\left(\mathrm{g} / \mathrm{m}^{2}\right)$ & $0.31 * *$ & 0.06 & $0.50^{* *}$ & $0.79 * *$ & & \\
\hline Total body BMD $\left(\mathrm{g} / \mathrm{m}^{2}\right)$ & $0.54 * *$ & $0.22 *$ & $0.68^{* *}$ & $0.81 * *$ & $0.85 * *$ & \\
\hline LPA (MET h/week) & 0.19 & 0.03 & $0.25^{*}$ & $0.24 *$ & $0.33 * *$ & $0.33 * *$ \\
\hline
\end{tabular}

In the current study, 16 men were classified as osteopenic (defined by a T-score between -1.0 and -2.5 SD, at any site) ${ }^{(4)}$ and one was classified as osteoporotic (defined by a T-score at or below $-2.5 \mathrm{SD}$, at any site) ${ }^{(4)}$. Furthermore, one man (19 years) was classified as having low bone mass for age (defined by a $Z$-score $\leq-2.0)^{(5)}$. Overall, 18 out of the $98(18.4 \%)$ healthy young males in this group were classified as having a BMD lower than normal. BMD at all sites was significantly and positively correlated with body weight, driven by the correlations with FFM as opposed to FM. Mean weekly LPA levels, controlling for age, also correlated positively with BMD.

In conclusion, if the prevalence of low BMD observed in the current study is representative of the young adult population, then greater priority needs to be focused on public health initiatives aimed at maximising peak bone mass at this critical age for bone health.

This work was funded by the Department for Employment and Learning. Ethical approval was obtained from the University of Ulster Research Ethics Committee.

1. National Osteoporosis Society (2009) Key Facts and Figures. http://www.nos.org.uk/NetCommunity/Page.aspx?pid=328\&srcid=312 (assessed March 2010).

2. Bonjour JP, Theintz G, Law F et al. (1994) Osteoporos Int 4, 7-13.

3. Horigan G, Barnes MS, Dalrymple D et al. (2007) Proc Nut Soc 66, 89A

4. World Health Organisation (2003) Technical Report Series No. 921.

5. Lewiecki EM, Gordon CM, Baim S et al. (2008) Bone 43, 1115-1121. 